\title{
Effect of Sex and Age of Human on Infection With Types of Stones and Its Concomitant Bacteria
}

\author{
Dr. Amera M. M. AL-Rawi \\ College of Science \\ Dept. of Biology \\ University of Mosul
}

\author{
Rash N.H.A. AL-Sa'doon \\ College of Education for Girls \\ Dept. of Biology \\ University of Mosul
}

\section{Received Accepted \\ 21/01/2018 09/06/2018}

\begin{abstract}
The current study involved isolation and identification of bacteria from (50) urine samples of patients suffering from renal stones and urinary tract infections (UTIs) Sixteen bacterial isolates were obtained from urine samples (32\%), Proteus mirabilis and Escherichia coli being the most frequent among isolates, forming 37.5\% (6 isolates) and $31.5 \%$ (5 isolates) respectively while Klebsiella pneumoniae isolates $12.5 \%$ (2 isolates) then Enterobacter aerogenes, Pseudomonas aeruginosa, Staphylococcus aureus were isolated at a rate of $(6.25 \%)$.

The study showed that $32(64 \%)$ of urine samples were from patients having calcium stone, $10(20 \%)$ with uric acid stone and $8(16 \%)$ with struvite stone but cystine stones were not identified. Furthermore, this study showed that there is a relationship between type of stones and the type of bacterial isolate .

The effects of some factors such as sex and age on the rate of infection with different stone types were investigated ,the results revealed that among (32) calcium stones, $71.9 \%$ were males and $28.1 \%$ were females. From (8) struvite stones, males represent $37.5 \%$ while females were $62.5 \%$, for uric acid stone $60 \%$ were males and $40 \%$ were female.

The incidence of renal stone seem to be the highest in the age group(30_53) years comprising $48 \%$ of the total patients followed by the age group (54_77) years $32 \%$ and the least incidence was in the age group (6_29) years $20 \%$.
\end{abstract}

Keywords: proteus mirabilis, type of stone 


\section{تأثير الجنس والعمر للإنسان على الإصابة بأنواع حصى الكلى والبكتربا المرافقة لها}

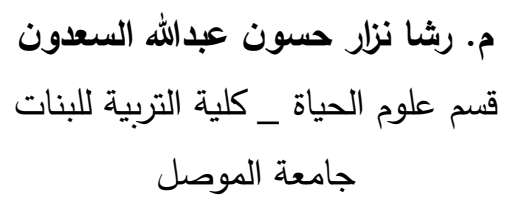

أ.د.أميرة محمود محمد الزاوي

قسم علوم الحياة _ كلية العلوم

جامعة الموصل

\section{تاريخ الاستلام ت إيخ القبول \\ 2018/06/09 2018/01/21}

\section{الملخص}

تضمنت الدراسة الحالية عزل وتشخيص البكتريا من 50 عينة ادرار لمرضى مصابين بحصى الكلى

واخماج القناة البولية، بلغ عدد عزلات البكتريا (16) عزلة مختلفة وبنسبة (32\%) من عينات عندات الادرار وكانت Escherichia coli و Proteus mirabilis (5 عزلات) على التوالي، اما Klebsiella pneumoniae فقد شكلت 12.5\% (عزلتين)، تلتها Enterobacter Staphylococcus aureus و Pseudomonas aeruginosa aerogenes

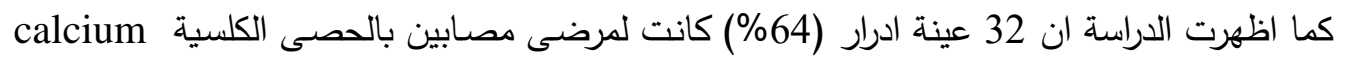

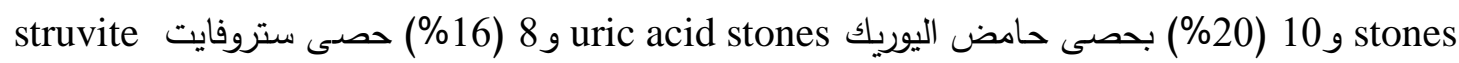

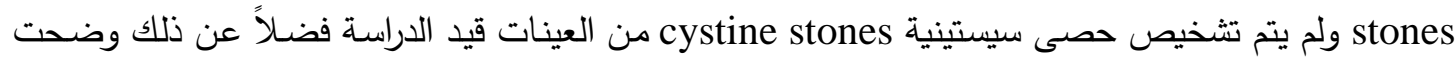
الدراسة ان هناك ترابطاً بين نوع الحصى ونوع البكتريا المسببة للاصـابة وان حصى الاخماج ستروفايت اظهرت اكثر انواع الحصى ارتباطاً بالإصابات الجرثومية. وتم التحري عن تأثير بعض العوامل كالجنس والعمر على نسبة الاصابة بانواع حصى الكلى واظهرت

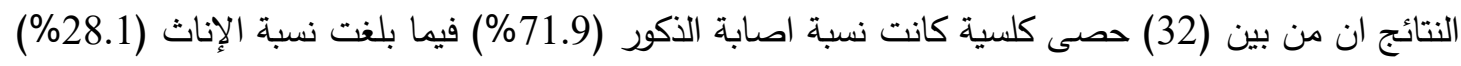
اما بالنسبة لحصى الستروفايت البالغ عددها (8) فقد كانت نسبة الذكور (37.5\%) والاناث (62.5\%) وبلغت نسبة الذكور المصابين بحصى حامض اليوريك (60\%) ونسبة الاناث (40\%)، وبينت النتائج ان الاصدابة

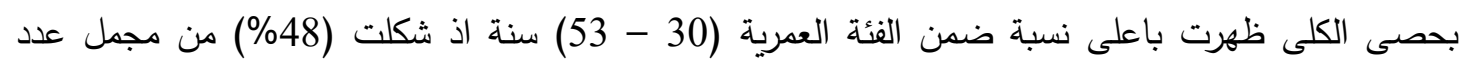

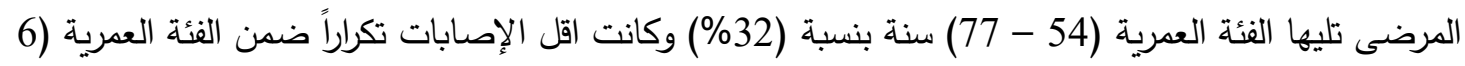
- 29) سنة اذ بلغت (20\%). 


\section{المقدمـة}

تتكون حصى القناة البولية أو الحصيات البولية أما في حوض الكلية او المثانة البولية وهي عبارة عن

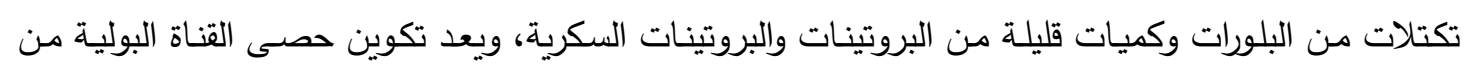
الإمراض الثائعة في مختلف أنحاء العالم عموما ومن الأمراض المتوطنة في الدول النامية والأكثر شيوعا بين

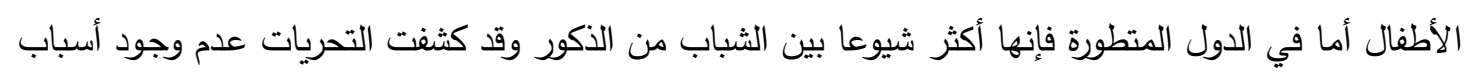

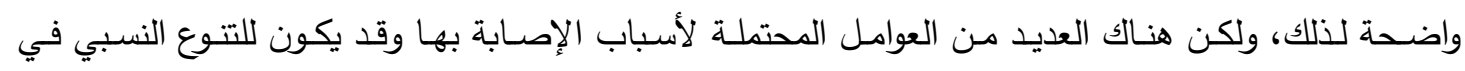
الخصائص شبه البلورية ومضادات التبلور في الإدرار دورا فيها [1].

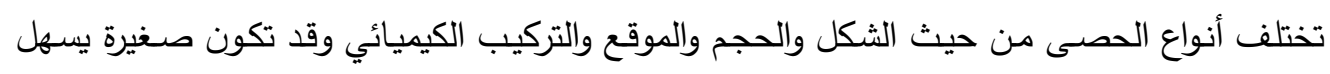

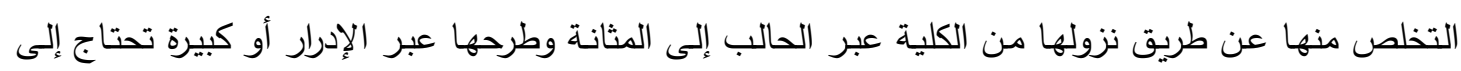

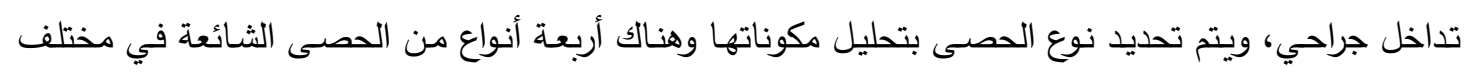
إنحاء العالم هي الحصى الكلسية calcium stones (الشكل 1) وحصى ستروفايت

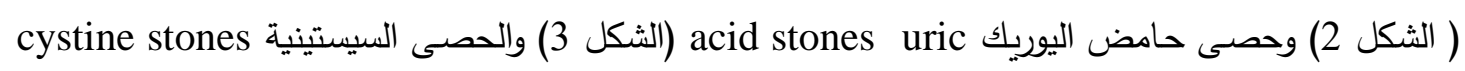

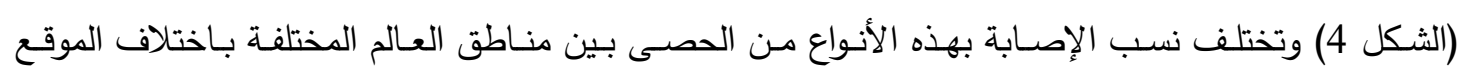

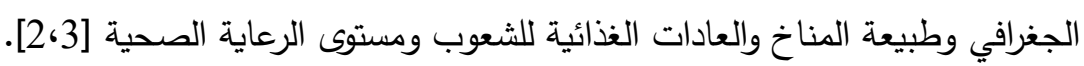

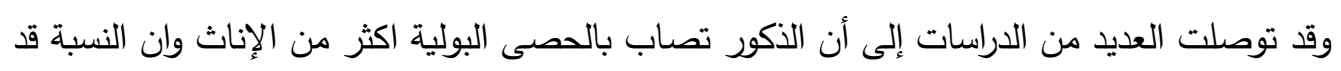

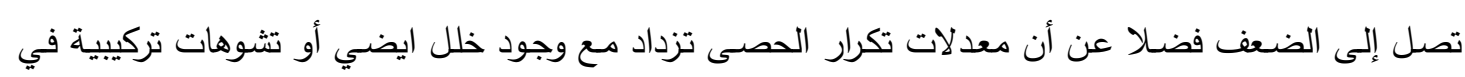
الجهاز البولي كما تتكون معظم الحصيات البولية من اوكزالات الكالسيوم مـع الفوسفات وهي الأكثر حدوثا في تُوني الذكور أما حصى الاخماج struvite التي تشكل (15\%) من إجمالي الحصيات البولية التي تكون أكثر حدوثا

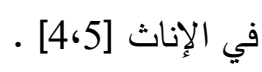

تتكون حصى الاخماج نوع struvite عند وجود الاخماج البولية لاسيما المرتبطة بالبكتريـا المنتجـة

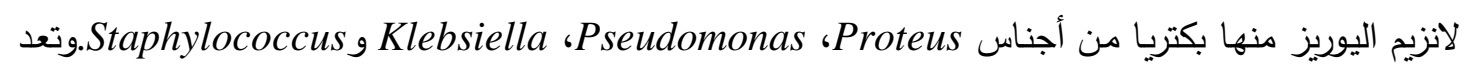

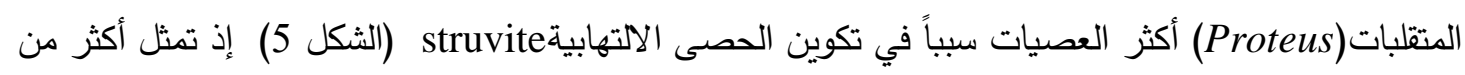

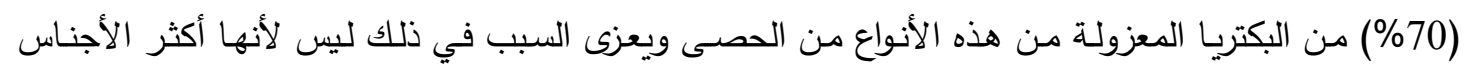

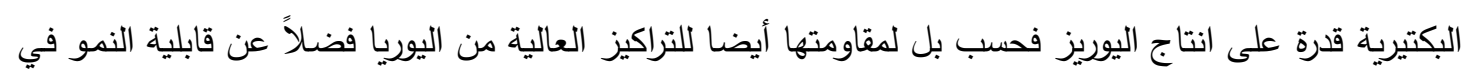

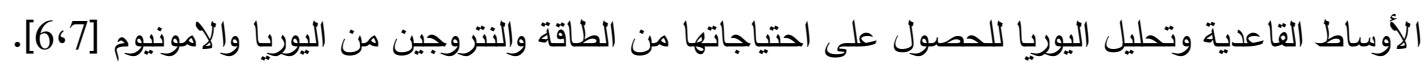

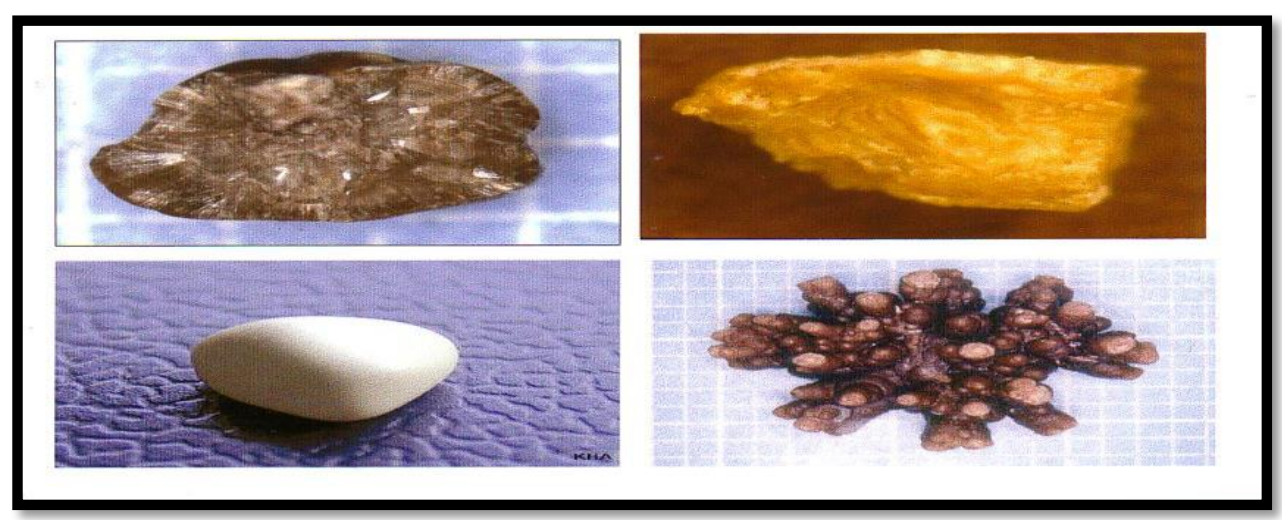

calcium stone الثكل (1) نماذج من الحصى الكلسية

Young and Keeley.[8] 
تأثير الجنس والعمر للإنسان على الإصابة بأنواع حصى الكلى والبكتريا المرافقة لها

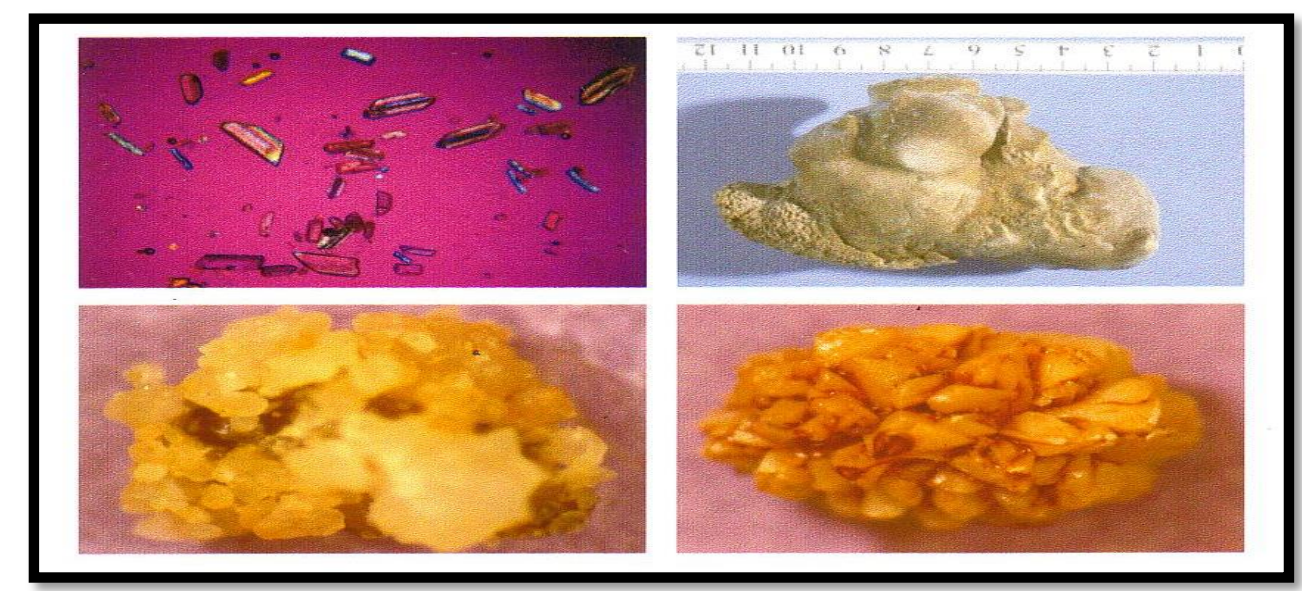

الشكل (2) نماذج من حصى الستروفايتstruvite stones Hruska. [9]

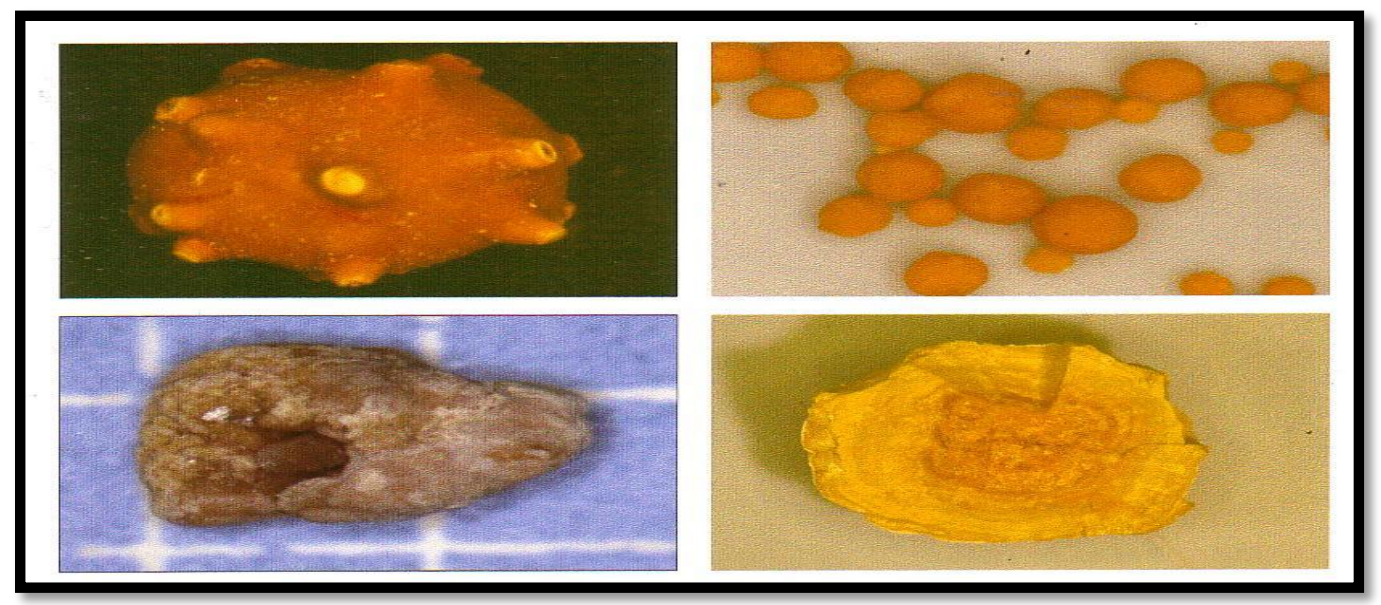

Uric acid stones الشكل(3) نماذج من حصى حامض اليوريك

Koka et al .[10]

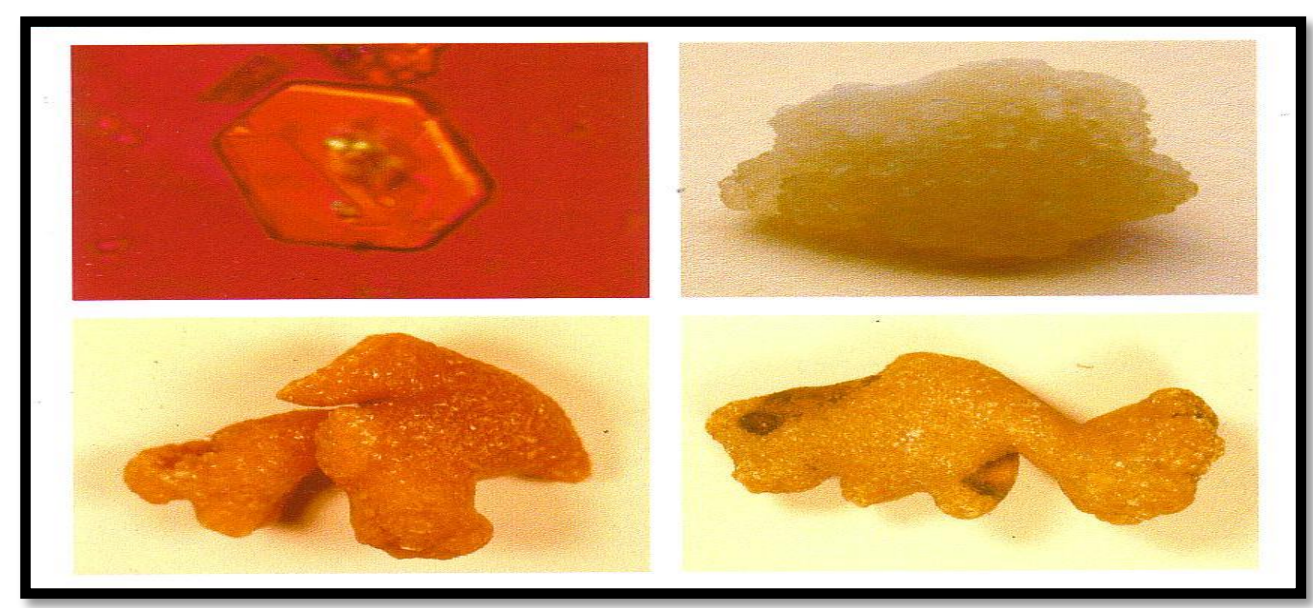

الثكل (4) نماذج من الحصى السيستينية cystine stones

Santos and Brouhard.[11] 


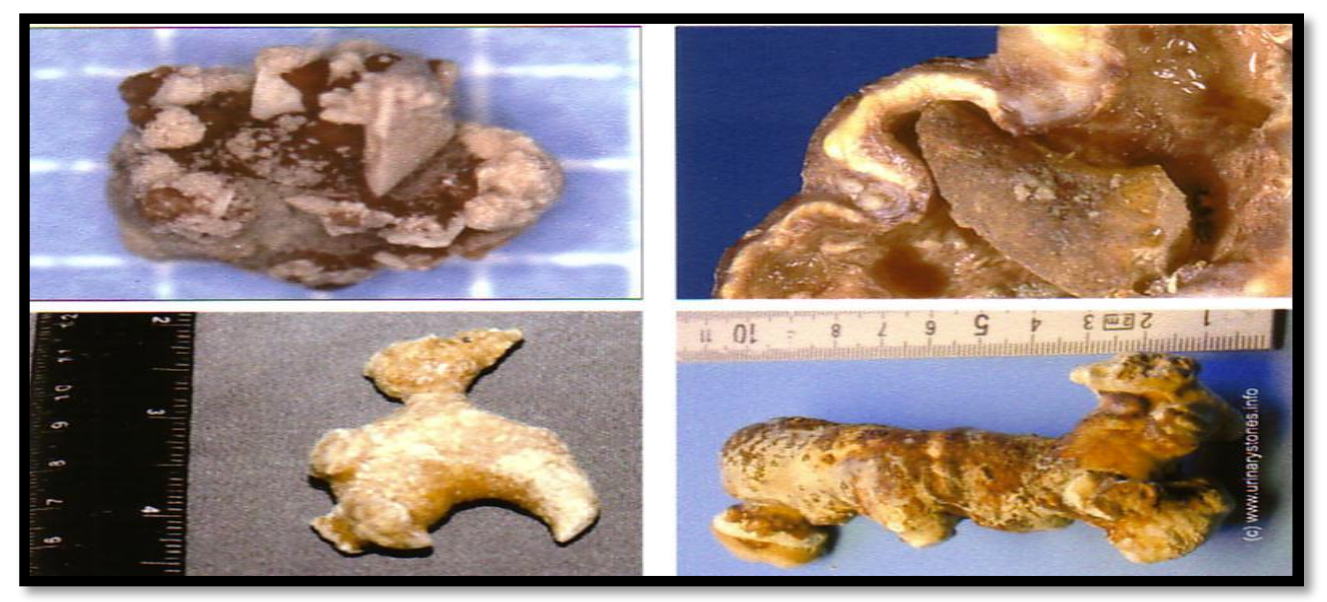

Staghorn الثكل (5) نماذج من حصى الستروفايت بثكل قرون الأيل

Segura et al .[12]

\section{المواد وطرائق العمل}

تم جمع (50) عينة من الإدرار الوسطي من مرضى مصابين بأنواع مختلفة من حصى الكلى (اعتماداً

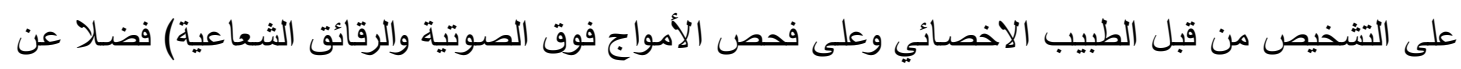

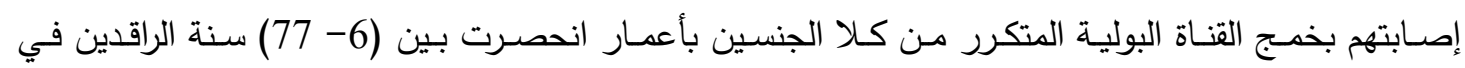

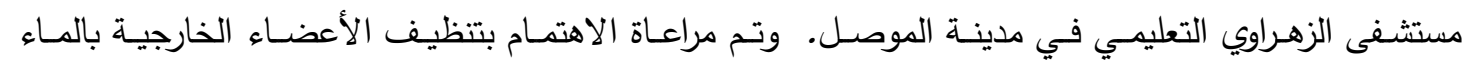

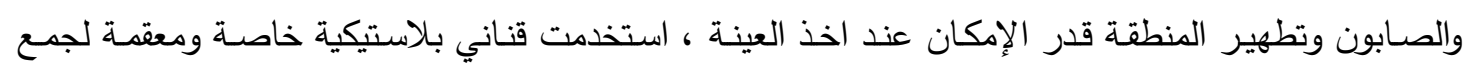

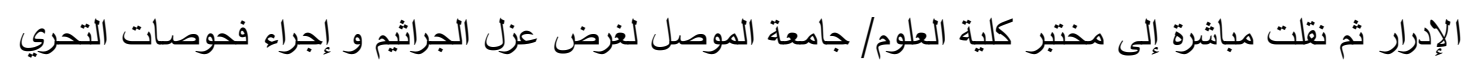

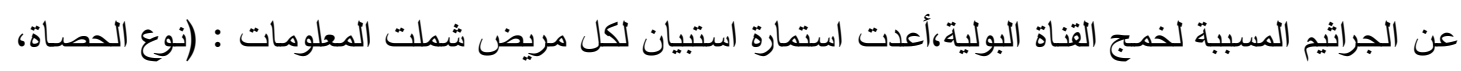

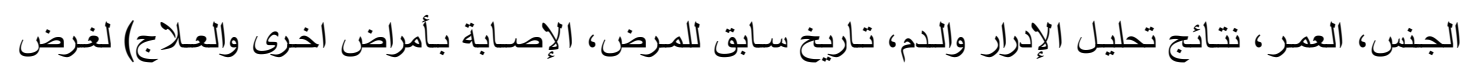
توضيح العلاقة بين حصيات الكلية وخمج القناة البولية ونوع الجراثيم المسببة لهار. عزل البكتريا:

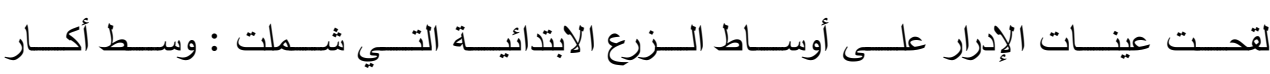
الماكونكي MacConkey’s Agar ووسط أكار الدم Blood Agar وحضنت الاطباق بدرجة حرارة (37)م لمدة (24) ساعة ولغرض إجراء الاختبارات الكيمياحياتية التشخيصية للبكتريا حفظت العزلات على شكل مزارع نقية على موائل الاكار المغذي. تثخيص البكتربا: تم اعتماد الاختبارات الثكلية والكيمياحياتية لتشخيص عزلات البكتريا من عينات الإدرار كما ورد في 


\section{النتائج والمناقشة}

بينت نتائج عزل البكتريا وتثخيصها من عينات الإدرار باعتماد الفحوصات الثكلية والكيمياحيوية عزل

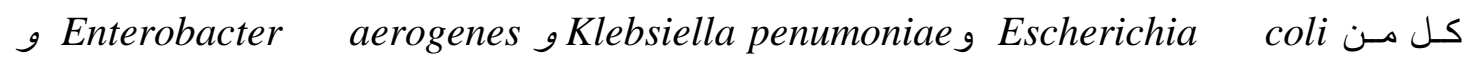
Pseudomonas aeruginosa الذي يبين أنواع البكتريا المعزولة البالغ عدد عزلاتها (16) عزلة اذ شكلت نسبة العزل(32\%) من عينات الإدرار

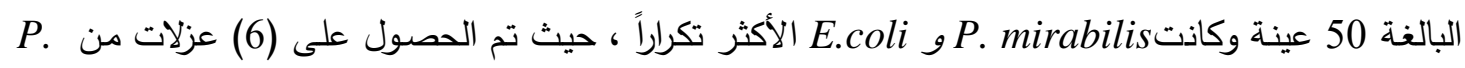
penumoniae وبنســبة (37.5\% mobilis Klebsiella Pseudomonas aeruginosa

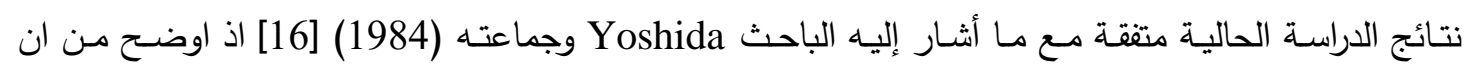
E.coli P. mirabilis بالد UTI وأنواع مختلفة من الحصى في دراستهم. كما أنها مقاربة لنتائج دراسة الباحث Nass وجماعته (2001)

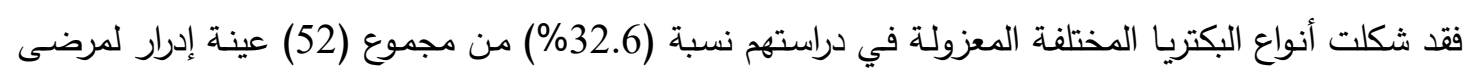

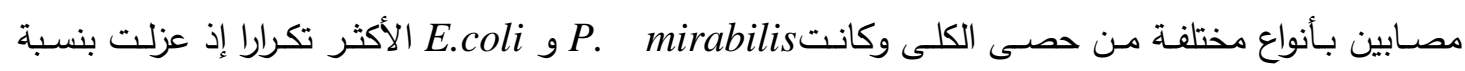

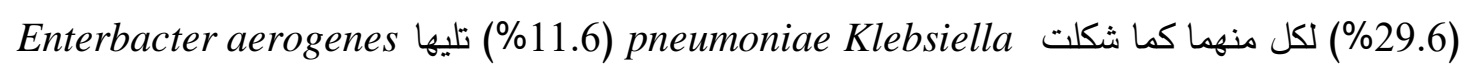

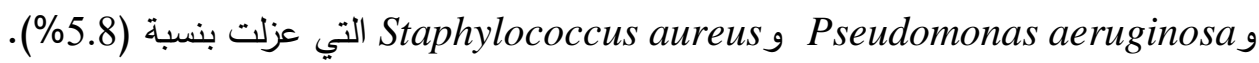

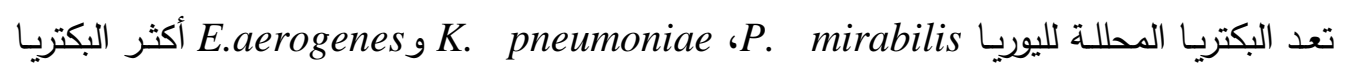
المعزولة من عينات الادرار للمرضى المصابين بحصى الكلى بسبب امتلاكها إنزيم اليوريز الذي يحلل اليوريا في الإدرار والذي له دور في تكوين حصى الكلى [18،17]. وتعزى نسبة العزل العالية للبكتريا E.coli

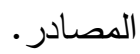

الجدول (1) أنواع ونسب البكتريا المعزولة من إدرار المرضى المصابين بحصى الكلى

\begin{tabular}{|c|c|c|}
\hline \multicolumn{2}{|c|}{ العزلات } & \multirow{2}{*}{ البكتريا المعزولة } \\
\hline$\%$ & العدد العد & \\
\hline 37.5 & 6 & Proteus mirabilis \\
\hline 31.25 & 5 & Escherichia coli \\
\hline 12.5 & 2 & Klebsiella penumoniae \\
\hline 6.25 & 1 & Enterobacter aerogenes \\
\hline 6.25 & 1 & Pseudomonas aeruginosa \\
\hline 6.25 & 1 & Staphylococcus aureus \\
\hline 100 & 16 & 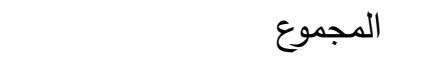 \\
\hline
\end{tabular}

العدد الكلي للعينات 50 عينة 
وعند التحري عن أنواع الحصى في المرضى المصابين بأخماج القناة البولية تبين ان (32) منها كانت

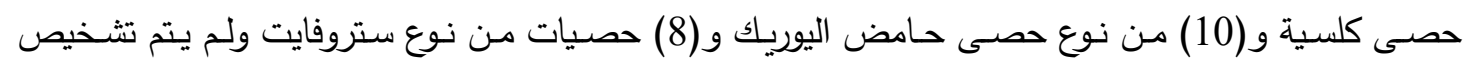

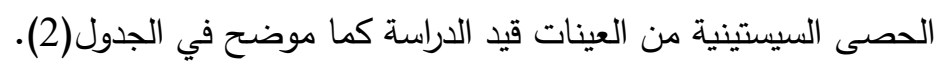
تختلف الإصـابة بأنواع الحصى تبعا لعوامل مختلفة منها مـا يرتبط بطبيعة المناخ والعادات الغذائية

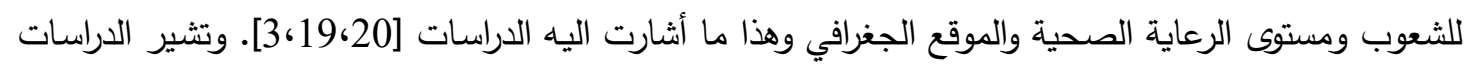
أن الحصاة الكلسية هي الأكثر شيوعا في معظم أنحاء العالم وتمثل (80\%) من مجموع الحصى تليها حصى مصى الستروفايت بنسبة (10\%) وحصسى حامض اليوريك بنسبة (5\%) أمـا الحصسى السيستينية فهي الأقل تكرارا وبنسبة (19،21،22]

الجدول (2) أنواع الحصى من المرضى المصابين بحصى الكلى واخماج القناة البولية

\begin{tabular}{|c|c|c|c|c|}
\hline \multicolumn{4}{|c|}{ انواع الحصى } & \multirow{2}{*}{ العدد الكلي للمرضى } \\
\hline سيستينية & حامض اليوريك & ستروفايت & كلسية & \\
\hline$(\% 0.0) 0$ & $(\% 20) 10$ & $(\% 16) 8$ & $(\% 64) 32$ & 50 \\
\hline
\end{tabular}

\section{العلاقة بين نوع الحصى والبكتريا المرافقة لها}

اظهرت الدراسة ان هنالك ترابطاً بين نوع الحصى ونوع الجراثيم المسببة للإصـابة في القناة البولية وان النيان

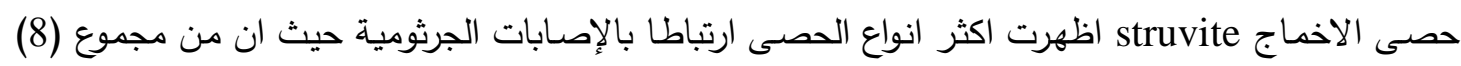

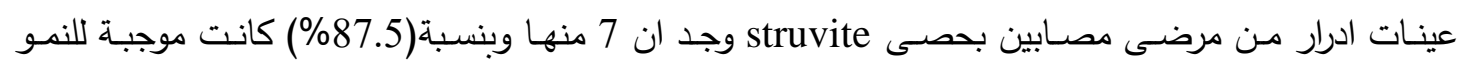

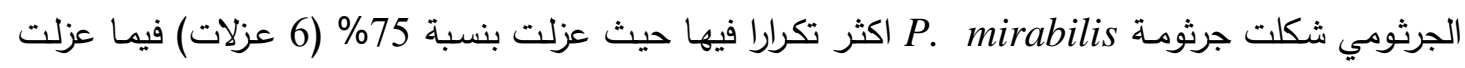
جرثومة Pseudomonas aeruginosa بنسبة 12.5\% (عزلة واحدة) اما الحصى الكلسية فقد وجد ان من مجموع (32) عينة إدرار من المرضى المصابين بهذا النوع من الحصى وجد ان 8 (25\%) فقط أظهرت نتائج

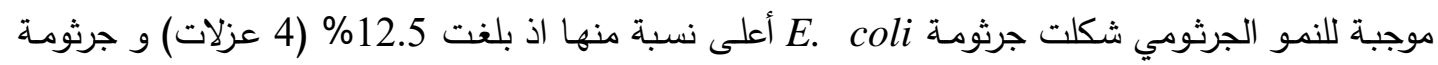

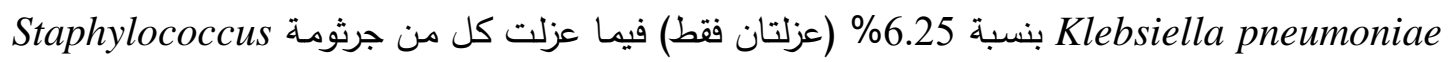
aureus, Enterobacter aerogenes

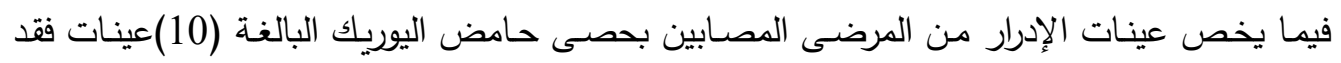

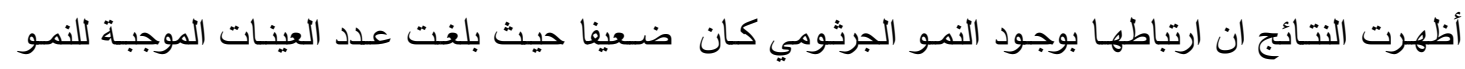

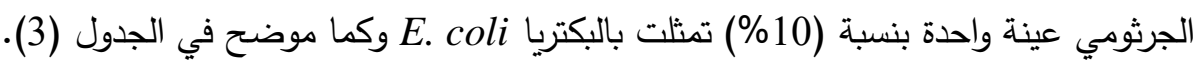


الجدول (3) أنواع وأعداد البكتريا ونسبها المئوية المعزولة من عينات الادرار للمصابين بالحصى

\begin{tabular}{|c|c|c|c|c|c|c|c|c|c|}
\hline \multirow{3}{*}{$\begin{array}{c}\text { العالبة } \\
\text { العينات } \\
\text { (\%) }\end{array}$} & \multirow{3}{*}{$\begin{array}{c}\text { الموجبة } \\
\text { العينات }\end{array}$} & \multicolumn{6}{|c|}{ أنواع البكتريا } & \multirow[b]{3}{*}{ عينات عداد } & \multirow[b]{3}{*}{ الحصاة } \\
\hline & & \multicolumn{6}{|c|}{ العدد (\%) } & & \\
\hline & & 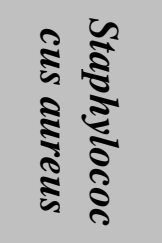 & 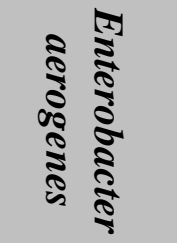 & 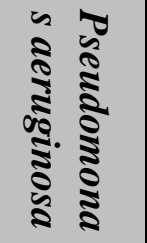 & 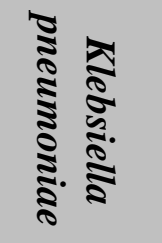 & 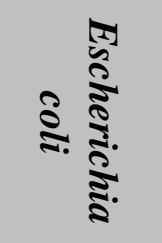 & 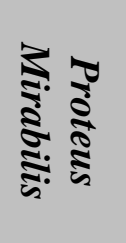 & & \\
\hline$(\% 75) 24$ & $(\% 25) 8$ & $(3.125) 1$ & $(3.125) 1$ & 0 & $(6.25) 2$ & $(12.5) 4$ & 0 & 32 & كلسية \\
\hline$(\% 12.5) 1$ & $(\% 87.5) 7$ & 0 & 0 & $(12.5) 1$ & 0 & 0 & (75) 6 & 8 & ستروفايت \\
\hline$(\% 90) 9$ & $(\% 10) 1$ & 0 & 0 & 0 & 0 & $(10) 1$ & 0 & 10 & اليوريك \\
\hline
\end{tabular}

تأثير عاملي الجنس والعمر:

اولا : الجنس

لبيان تأثير الجنس على نوع الحصاة فقد بينت نتائج الدراسة ان من مجموع (32) حصى كلسية كانت

نسبة إصابة الذكور (71.9\%) في حين بلغت النسبة المئوية للاناث (28.1\%) اما بالنسبة لحصى النير الستروفايت

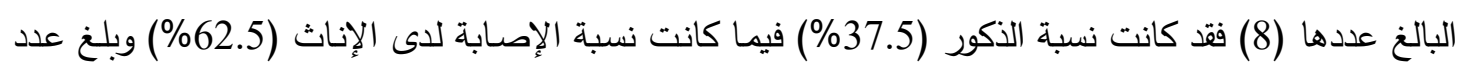

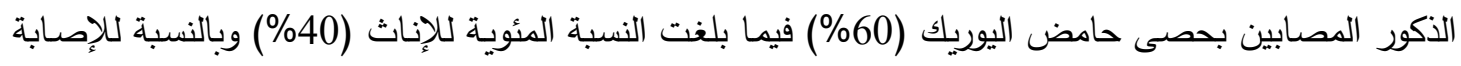

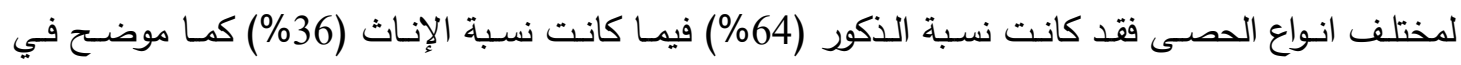
الجدول(4).

الجدول (4) تأثير الجنس على الإصابة بأنواع الحصى

\begin{tabular}{|c|c|c|c|c|c|}
\hline \multicolumn{2}{|c|}{ الاناث } & \multicolumn{2}{|c|}{ الذكور } & \multirow{2}{*}{ العدد العد } & \multirow{2}{*}{ نوع الحصاة } \\
\hline$\%$ & العدد & $\%$ & العدد & & \\
\hline 28.1 & 9 & 71.9 & 23 & 32 & كلسية \\
\hline 40 & 4 & 60 & 6 & 10 & حامض اليوريك \\
\hline 62.5 & 5 & 37.5 & 3 & 08 & ستروفايت \\
\hline 36 & 18 & 64 & 32 & 50 & المجموع \\
\hline
\end{tabular}

أشارت العديد من الدراسات أن الذكور أكثر تعرضا للإصـابة بالحصى الكلسية مقارنة بالإناث والسبب

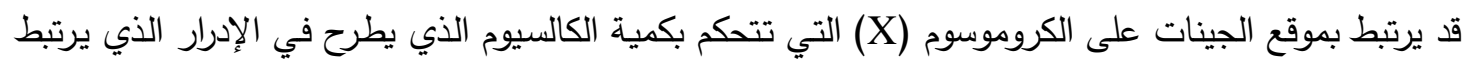

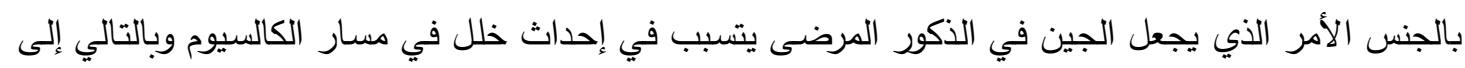
زيادة كميته في الإدرار وتكوين الحصى, فضلا على ذلك الاختلافات التركيبية في الجهاز البولي وطبيعة العدل 
والظروف البيئية والأنماط الغذائية وغيرهـا ، وان الإناث أكثر إصـابة من الذكور بحصى الستروفايت بسبب

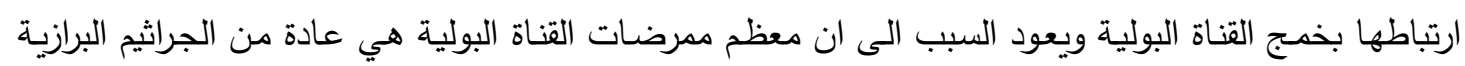
التي تدخل عن طريق مجرى الإدرار ويعد قصر الاحليل لدى الأنثى من العوامل التي تسهرل هذه العملية

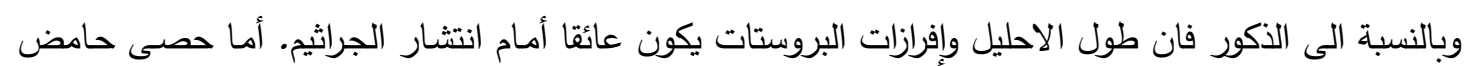

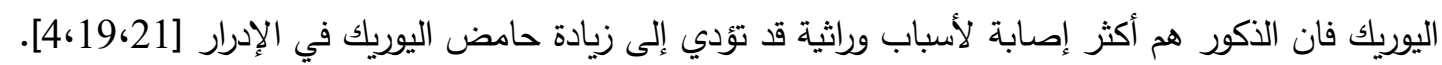

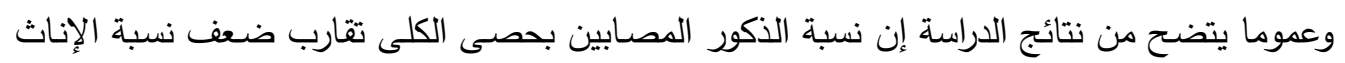

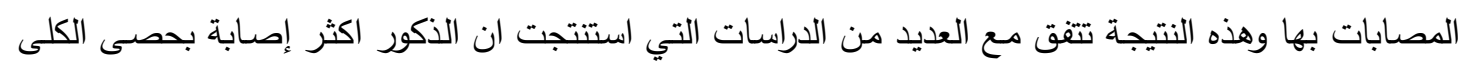
مقارنتة بالإناث وان النسبة قد تصل الى الضعف وهذا ما وجد في كل من المملكة العربية السعودية وليبيا و

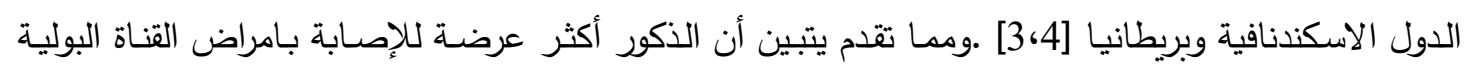
العليا (حصى الكلى) والإناث أكثر عرضة للإصابة بخمج القناة البولية السفلى (خمج المثانة).

ثانيا : العمر تظهر النتائج الموضـحة في الجدول (5) بان أعلى نسبة للإصـابة بحصى الكلى كان ضـمن الفئة

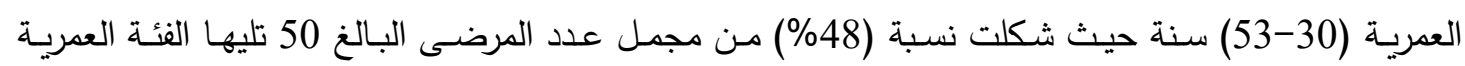

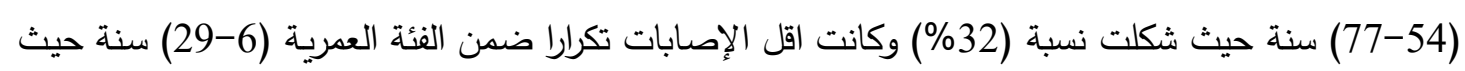
بلغت (20\%). إن النتائج التي توصلنا اليها مقاربة لنتائج العديد من الدراسات في دول مختلفة من العالم حيث أشارت

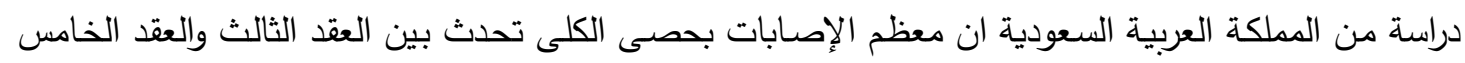

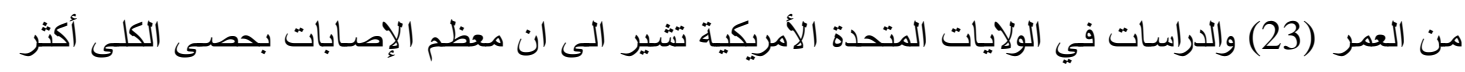

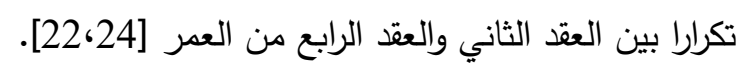
كما أشار [3] الباحث Hasslett وجماعته (1999) ان الإصـابة بحصى الكلى تكون أكثر شيوعا بين

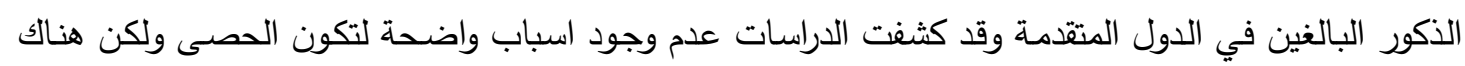

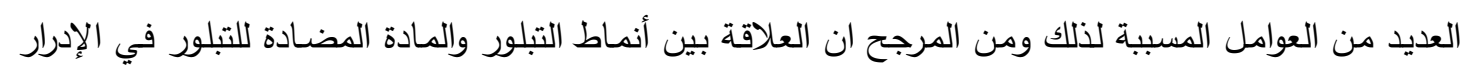
لها أهمية من الناحية العملية.

\begin{tabular}{|c|c|c|}
\hline & المرضر & الفئة العمريـة \\
\hline$\%$ & العدد & (سنة) \\
\hline 20 & 10 & $29-6$ \\
\hline 48 & 24 & $53-30$ \\
\hline 32 & 16 & $77-54$ \\
\hline
\end{tabular}




\section{المصادر}

1.Ziyadeh, F.N. and Goldfarb, S. Nephrolithiasis. In Dc Dale, DD Federman, eds. ACP Medicine, Section 10, Chap. 12. New York: WebMD (2005).

2.Minevich, E. Pediatric urolithiasis. Pediatric clinics of North America, 48(6): 1571 1585 (2001).

3. Haslett, C.; Chilvers, E. R.; Hunter, J. A. and Boon, N. A. Principles and practice of medicine. eighteenth edition, Davidson's. British Library (1999).

4. Nass, T.; Al-Agili and Bashir, O. Urinary Calculi: bacteriological and chemical association department of Urology, Tripoli Medical center, Tripoli, Libyan Arab jamahiriya. Vol. 7, p. 756-762 (2001).

5.Johri, N.; Cooper, B. ; Robertson, W. ;Choong, S. ;Rickards, D. andUnwin, R. "An update and practical guide to renal stone management". Nephron Clinical Practice 116 (3): c159-71 (2010).

6. Coker, C.; Poore, C. A.; Li, X. and Mobley, H. L. T. Pathogenesis of Proteus mirabilis urinary tract infection. Microbs Infect. 2 : $1497-1505$ (2000).

7. Rodman, J.S. struvite stones. Nephron 81 (Suppl.1), 50-59 (1999).

8.Young, J.G. and Keeley, F.X. Chapter 38: Indications for Surgical Removal, Including Asymptomatic Stones, pp. 441-54 in Rao, Preminger and Kavanagh (2011).

9.Hruska,K.A.(2004).struvite and stones.CELIE.Text Book of Medicine.

10.Koka, R. M.; Huang, E. and Lieske, J. C. Am. J. Physiol. Renal Physiol., 278 : 989 - 998 (2000).

11. Santos - Victoriano, M. and brouhard, B. H. Clinical Pediatrics, 37 (10) : 583 594 (1998).

12. Segura, J. W.; Preminger, G. M. and Assimos, D. G. Nephrolithiasis clinical guidelines panel summary report on the management of staghorn calculi. The American urological association nephrolithiasis clinical guidelines panel. J. Urol. Jun; 151 (6) : 1648-1651 (1994).

13. Koneman, E. W.; Allen, S. D.; Janada, W. M.; Schreckenberger, P. C. and Winn, W. C. Color atlas and text book of diagnostic microbiology. $5^{\text {th }}$ ed., LippincottRaben publishers, Philadelphia, USA (1997).

14. Prescott, L. M.; Harley, J. P. and Klein D. A. Microbiology. $3^{\text {rd }}$. ed. WMC. Brown communication, Inc., Iowa, U.S.A (1996).

15.Macfaddin, J.F. Biochemical tests for identifiaction of medical bacteria. $2^{\text {nd }}$. Ed., Waverly press, Inc., Baltimore, U.S.A (1985).

16. Yoshida, O.; Kiriyama, T.; Okada, K.; Okada, Y.; Watanbe, H.; Mishina, T.; Uchida, M.; Watanbe, K.; Tomoyoshi, T. and Takayama, H. A bacteriological study on urinary calculi associated with infections. Hinyokika Kiyo. Feb; 30(2): 191-198 (1984).

17. Li, X.; Zhao, H.; Lockatell, C. V.; Drachenberg, D. E.; Johnson, D. E. and Mobley, H. L. Visualization of Proteus mirabilis within the matrix of ureaseinduced bladder stones during experimental urinary tract infection. Infect. Immun. Jan; 70 : 389 - 394 (2002).

18. Kramer, G.; Klingler, H. C. and Steiner, G. E. Role of bacteria in the development of kidney stones. Curr. Opin. Urol. $10: 35$ - 38 (2000).

19. Robert, J. C. Kidney stones, general Adult and Prosthetic Urology. Web site: http://www.urosurgeryhouston.com.htm. (2003).

20. Goldfarb, D. S. and Coe, F. L. Americans family physician, 60 (8) : 2269 - 2277 (1999). 
21. Joseph, F. S. Kidney stone. Medical library, 333 pine Ridge Blvd. Wausau, WI 54401. Web site : http://www.chclibrary.org (2005).

22. Kodama, R. Renal colic - new treatment. Smith's General Urology, article (2004).

23.Kassimi, M. A.; Abdul-Halim, R. and Hardy, M. J. The problem of urinary stones in western region of Saudi Arabia. Saudi medical. J. 7 (4) : 349 - 401 (1986).

24. Victorian, R. ; Haluk, A. and Dean, G.A. Kidney Stones: A Global Picture of Prevalence, Incidence, and Associated Risk Factors.Rev Urol. Spring-Summer; 12(2-3): e86-e96 (2010). 